\title{
The Specter of Automated Creativity
}

BY VERN M. PINGS

THE FIFTEEN YEAR OLD WORD, cybernetics, identifies not only the technological revolution of automation, but a metaphysical revolution. Because of its breadth of conception, cybernetics seems to cut across all disciplines. This is not an unheard of event in the history of ideas. Newton summarized in one swoop man's knowledge of the universe, giving the world the metaphysics of materialism on which most of science rests today. Darwin's summary of the biological world under evolution caused a change of attitude in many fields.

Cybernetics is, as are all metaphysical systems, a pseudoscience. But like evolution or Einstein relativity, cybernetics is too new and still too useful to be admitted by most people to be pseudoscientific. Astrology and phrenology, which still guide a not-insignificant number of people, also had their period of ascendency. A metaphysical system's intellectual function is to stimulate the imagination through analogy and metaphor. But unwise use of analogy can be misleading. When a phrenologist equates lumps on the head with lumps in the personality, we call this unscientific. When an engineer (or a physiologist) programs a computer to do something never before done by a machine and says it simulates some human function, for example, thinking, is he really being scientific? Analogies are not in themselves bad, because if we are going to communicate at all, we must at some point use analogies. To say relativity and astrology are metaphysical does not mean they are the same and that one can be understood in terms of the other. A tremendous difference exists,
Mr. Pings is Librarian of the College of Medicine, Wayne State University, Detroit.

both logically and practically, between saying that two things are the same and saying that they seem to share some conceptual attributes.

The man-machine analogy of the cyberneticists has invaded the very organization of science. Arguments are presented not only for philosophic or scientific discussion, but are used to acquire research funds and to increase the budgets of bureaucracies. Anyone who says he needs a computer in his research or in his work has an immediate boost in status. These dreamers who say they can create a machine which thinks, learns, or makes decisions have forgotten one thing: no one knows how, or even why, man thinks, learns, or makes decisions. Nevertheless bold statements are made that machines can carry on such life functions.

In the study of life and its characteristics we have always been plagued with certain methodological problems. The cyberneticists have, in many instances, failed to realize they are not immune from these methodological considerations. When a researcher studies an organism, he must impose conditions on it which modify the organism's functioning. Since an organism is intimately related to its environment, the researcher can not know for certain what elements belong to the organism's functions and what belong to the environment. Further, the researcher in setting up his study usually uses physico-chemical tools. 
One should not be surprised then if his conclusions are stated in physicochemical terms. On the other hand, if one assumes a particular property is characteristic of some life process and then this property is discovered in an inanimate object, the conclusion is easy to make that the object is alive. The fallacy in this anthropomorphizing rests in the $a$ priori assumption that certain characteristics are confined to a living organism. When the belief becomes common that an inanimate object is homologous to life, this mere assumption is then often accepted as fact: if one studies this object, information will be revealed about the behavior of life. The study of life processes by homologies, while more restrictive and hence subject to fewer "errors," can be just as spurious as study by analogy. ${ }^{1}$

No matter how critical one can be about the metaphysics of cybernetics, or its methodologies, no one can dispute that a machine has been injected into the fabric of our culture which can deal with matters on a new and different level even if it does not explain the reality of life. As a librarian I am supposed to be dealing with knowledge, organizing it so that the creators of knowledge can get reinforcements and so that the seekers of knowledge can find what is known. My purpose in pointing out the fallacy in man-machine analogies and homologies is to try to gain a perspective. If the engineer-physiologist really knew how the brain operated (which he implies when he states he has designed a machine which "thinks"), we would know how knowledge is created. If we knew how knowledge is created, we would have less difficulty organizing it. But the moment we use the word knowledge we have moved to metaphysical problems rather than to descriptions of life processes or machine components. Before we

1 Arnold M. Ludwig, The Mystery of Life. (Springfield, Ill.: Thomas, 1961), pp. 7-11. Cf. also Mortimer Taube, Computers and Common Sense. (New York: Columbia University Press, 1961). start applying expensive computers to epistemic problems, I feel we should be aware of what is physics and what is metaphysics.

When we speak of knowledge in an academic tone of voice, what is usually meant is that which is found in books and journals, i.e., communicable through symbols. The scientist is very rigid about this. He is little concerned about the savoir faire, his aim is the savoir. The farmer can teach his son how to farm, but the agriculturist wants to know the why, he wants things defined and classified to see the relationships that exist. To the scientist events must be demonstrable through symbols, not just teachable.

Whitehead was perhaps the first to point out that it was the yeasty Middle Ages that gave science this faith in words and logic. ${ }^{2}$ To the medieval Schoolmen knowledge was arrived at through the use of reason. Reason, for them, consisted in logical argument. What could be explained logically was truth. They trusted logic because it could produce coherent systems. The fact that the systems may have had little acquaintanceship with what man actually experienced was unimportant. Their method of furthering knowledge, from our point of view, was endless debate. These debates produced little new knowledge, but they did stamp the Western scholar with the necessity to adhere to Occam's razor. In modern terms this amounts to saying that any theory, to be of value, must state everything of interest with logical coherence and in the simplest way. "It is vain to do with more what can be done with fewer."

The wordy debates of the Scholastics were supplemented in the sixteenth century by the Baconian dictum: observe, observe, observe. The scientists began to confine themselves to talking only about the things they observed, nevertheless they still retained the Scholastic's atti-

2 Alfred North Whitehead, Adventure of Ideas. (New York: Macmillan, 1933), p. 121. 
tude for logical coherence. Distrusting the medieval logomachies they were not content to use ordinary words; they required their explanations be reduceable to mathematical logic. When the observed events of nature could be explained in mathematical symbols, they felt they had found a law of nature. The scientists did not abandon the reason of the Scholastics; they transferred it from man to nature. Man can be unreasonable, but nature will never break one of her laws. To the materialistic scientist this means that all nature is continuous and operates under the same laws. This belief in the validity of man-made, mathematically-stated laws which express the reality of nature is with us today and governs the thinking of many scientists. Ledley writes,

Ultrasonic receptors in bats enable these animals to fly successfully through a maze of wires in spite of total darkness and loud external noise ... some snakes have infrared energy detectors; and so forth. The biological operation of such mechanisms is based on the same laws of physics and chemistry that the operation of transistors and other components devised by man is based on. ${ }^{3}$

To say that the laws we have derived for transistor function are complete and thus universal or are the same as those for the auditory physiology of a bat is certainly debatable.

Whether nature is actually all of a unity is an unanswerable question at present, and forty years ago physicists gave a mathematical proof that demonstrates that the question will always be unanswerable. The question Heisenberg asked in 1925 which created a whole new science, quantum physics, was "What is it we really observe in an atom?" 4 His answer amounted to this: since the physicist cannot see atomic particles, he must devise some measuring instrument that extends his senses. Atom-

${ }^{3}$ Robert S. Ledley and Lee B. Lusted, "Biomedical Electronics: Potentials and Problems." Science, CXXXV (1962), 198-201.

Arthur Stanley Eddington, Philosophy of Science. (New York: Cambridge University Press, 1939). ic particles are so small and so rapidmoving that anything used to measure them also disturbs them-like trying to pin down a drop of mercury with a bulldozer blade. Since the atomic physicist is never quite sure what he has measured, his only recourse is to make many measurements to build a statistical picture. But when the statistician creates such an entity as an "average man," there is no entity in nature which precisely fits the statistical description. The quantum physicist admits then that he can not predict what an individual atomic particle will do; the best he can do is to express atomic events in probability functions. If it is true that all of matter is made of atomic particles, and all of our knowledge of them is statistical, do we have any assurance that any description in words or mathematics fits any actual event in nature? These scientists, and the number is not a crackpot minority group, who still insist that man can know the absolute workings of nature through mathematically coherent descriptions, appear to be carrying on the tradition of the medieval Schoolmen who placed faith in their symbols while ignoring experienced fact. Like the engineer-physiologist who thinks his computer is a brain, this group assume the knowledge that is in books and journals is absolute.

While the quantum physicist was discovering that he had no evidence his symbolic representations had any equivalence to specific events and experiences, other groups also got into this epistemological fray, the philosophers and linguists. They did not ask the question in quite this context, but, if mathematical language does not refer to facts of existence, what is the nature of other symbolic means of communication, e.g., language or pictures. $^{5}$ This is an important question because Shannon, the creator of the famed information theory, has shown that any

5 Walter M. Elsasser, The Physical Foundations of Biology. (New York: Pergamon, 1938), pp. 14-19. 
symbolic representations, be they words, pictures, or electrocardiograms, can be reduced to a binary code which makes them handleable by a computer. One of the beauties of Shannon's theory is the complete quantification of information. Every "bit" of information has exactly the same value. This quantification, however, still leaves unanswered the metaphysical question of what knowledge is that the "bit" of information carries.

Here is the materialist's dream: a system is defined which places all symbols on the same logical level. But what happens to communication when all symbols have the same value? What we get is a series of additions and multiplications of symbols and nothing more. Adding stone upon stone means adding stone upon stone. When and how do we recognize that a pyramid is formed? When does a physician know that a certain set of symptoms can be identified as a syndrome?

As paradoxical as it may seem, the only way we can communicate meaningfully is to use words that are imprecise, or at least are many-leveled and manyvalued in explanatory power. ${ }^{6}$ The meaning of symbols depends on the values we place on them and these values are determined by our experiences. Since no two individuals can have precisely the same experiences, the meaning given a word, or a sentence, or a novel, will always vary as the human experiences vary. Imagine the difficulty in communicating if we couldn't change the significance of a word, e.g., electron, blood, or even justice, as our experiences expanded. While the process of communication helps us to secure, in some mysterious way, a gestalt of our experiences, the words and symbols are never all-inclusive. The most that can be said about knowledge conveyed through symbols is that it requires the agreement of men and is far from

\footnotetext{
Norwood Russell Hanson, Patterns of Discovery.
} (New York: Cambridge University Press, 1958), p. 60. revealing the universal laws of nature in formal or mathematical language.

To show just how far away we are from completely formalizing knowledge, i.e., classifying it into one complete system, or to say it another way, removing all the ambiguity from our words, one need only examine the efforts of mathematicians to reduce some simple games to a completely formalized process. Brown shows that the simple game of Goofspiel which is a matter of matching two suits of cards in a maximum of thirteen moves would require that $10^{20,000}$ strategies would have to be considered by the third move in the game. ${ }^{7}$ Shannon tells us that for a computer which can calculate one million moves per second to consider the aspects of the first move in a forty-move chess game would require $10^{95}$ years. To illustrate how meta-astronomical such figures are, one of the more recent estimates of the age of the solar system is a mere $10^{10}$ years. Even if engineers should increase the efficiency of computers by thousands of times, millions of years would still be required to play one game of chess. This may seem an impractical example since who wants to play chess with a computer anyway? But let us compare the metabolism of a liver cell with a game of chess, anabolism on one side and catabolism on the other. Already we know that the number of biochemical pieces and their possible moves would make the game of liver cell metabolism more complex than chess.

Since we do play chess and since we can understand something about liver cell metabolism, we must get this understanding through some means other than formal logic. Understanding does not come by adding piece of information on piece of information. The conclusion is obvious: a computer that acts completely logical is not a creative device. A creative computer would have to replicate, not

\footnotetext{
7 George W. Brown, "Computation in Decision Making," in Information and Decision Processes, ed. Robert E. Machol (New York: McGraw-Hill, 1960), pp. 1-14.
} 
simulate, a human being. Luckily nature has provided us with a more pleasurable way of replicating ourselves.

I am not "agin" computers. Far from it. Cybernetics as a metaphysical discipline is here to stay and to fight it would be like the fundamentalist arguing against evolution. My objection is the attitude proferred by so many that computers are going to solve man's problems. Existing and future computers are not going to solve anything, anymore than did the invention of the wheel, or the jet motor. The computer, as a device, like all creations of homo faber, from the ax on up, is going to change homo sapiens way of living, not supplant him. No one today would say that the invention of the printing press relieved man of the necessity for writing or of solving his problems. But the press did define new relationships between the governor and the governed and scholars with other scholars. The computer is going to permit similar realignments of social relationships and there is no doubt new definitions of human intercourse will have to be made because everything today seems to be "exploding" quantitatively.

When anything increases quantitatively, a point is reached where a qualitative change occurs. The sand on the beach piles up to form a dune, a dune grows to become a hill; the hill, given enough time, becomes a mountain. One does not climb a sand dune with the equipment used by a mountaineer. The electronic computer was constructed during the war to do the calculation of massive mathematical data. But not all data man possesses has qualitative significance worth calculating. The mathematician Cauchy showed over a hundred years ago that any group of numbers can form a series, that is to say, once we have data reduced to numbers, we can always make an empirical formula. The necessity for good judgment in science, or in business, has not changed one iota because we have a machine that can logically manipulate numbers.

In the area of judgment and decisionmaking a new literature has also arisen. What has occurred in industry and the military where the theory of "decision processes" has been applied is again an instance of increased quantity producing new qualitative relationships. A simple, but dramatic example of how growth alters the needs of an industry is in air transport. One can go to an airline office and ask for a reservation. The clerk selects the card for your flight, punches out the date, presses a button and in a matter of seconds knows whether space is available for you. We can, if we want, assign all kinds of anthropomorphic qualities to this operation. We asked the computer a question, it consulted its memory, and it gave an answer. If the answer is that no space is available, we can say the computer has made a decision that you cannot go on this flight.

More important than the question of whether computers make decisions is the fact that airlines are able to keep tabs on their flights with a computer. The increase in the number of flights, the increase in the number of passengers, and the increase in air speed gave the airlines a quantity of data that became unmanageable with the telephone and handwritten charts; the information had taken on new dimensions.

As industry and our military have changed qualitatively because of their growth, so have academic disciplines. Never before has the world had so many historians, scientists, and technologists, causing, as everyone knows, an increase in literary output. Because computers can deal with information (after all, we have a theory which says so) and because it is technically possible to reduce the information contained in the Library of Congress to a few cubic yards of film, some engineers have asserted that libraries can be reduced to a computer which 
can be tapped by picking up the phone, dialing an appropriate number, and getting an answer as we can now get a recorded weather report.

This may be realizeable some day, but remember, there is a difference between knowledge and information. The symbols and pictures of books are merely the carriers of knowledge. Engineers can photograph books, transmit them along wires or radio waves, and then retranslate them to their original symbols. Not one bit of new knowledge has been created in this process. Information as information is useless. Most of us could stare at the information contained in a book of Chinese characters until we are cyanotic and still not be able to get the knowledge the information is intended to convey. Knowledge, this ineffable something, to be created from information requires a community of men who work toward agreement. Information can be stored and retrieved in many novel ways, on clay tablets or in computers, but knowledge today, tomorrow, and forever has to be used and shared or else it is lost.

Before we place information in a computer memory on a grand scale, we shall have to reorganize our communication patterns. This reorganization is going on today at a much faster rate than many of us want to admit. This is taking place through socialization and further institutionalization of communication. To illustrate what I mean: sixty years ago it was still in the tradition for each scholar to have his own library. But the day of individual scholarly libraries is all but gone. The quantity of knowledge is now so large that the scholar to maintain a qualitative grasp of his work must go beyond the knowledge available to him in his own library. Consequently, ever larger and more complex interrelations with concomitant bureaucracies are being formed.

The reorganization of data for computer storage and retrieval has not been undertaken solely by government agen- cies or industry, but by adventuresome groups who expect to make a profit by selling a service. One such service is Mediphone, which purports to have all the pertinent information on the eight thousand drugs now in use in the United States. This information, they say, was gathered by research teams of physicians, pharmacologists, and toxicologists. What is interesting to note for a librarian is that when Mediphone is called for knowledge about a drug, the person who answers the phone is a physician who is supposed to be able to interpret the question asked of him and is also supposed to be able to evaluate the information given in the extensive card files. Here is a new kind of library: compiled and gathered by scientists and interpreted by scientists for scientists.

Examining the existing computer information systems two things are apparent. ${ }^{8}$ Only when the data or information has reached a certain quantity in a narrow area does it seem feasible to warrant the expense of reorganizing it for computer memories. This may seem obvious, nevertheless a good many individuals seem to think the day has arrived when all existing knowledge with its gaps and illogicalities can be put into a computer.

The other aspect of computer systems is the nature of the data and information that can be successfully manipulatedthe more abstract the data or information, the easier it is to adapt for computer handling. I am juggling words, but to get a grasp of applied cybernetics the distinction between abstract and concrete concepts must be understood. I want to reverse completely the usual interpretation of these words. The materialist scientist, remember, felt he dealt with facts of existence when he reduced what he visualized as a regularity in nature to mathematical logic. But mathematic statements are the most general of generalities and have little direct relation-

8 John W. Carr, "Better Computers," International 
ship to existence. To go back to the example of the airlines, the reduction of flights to a particular day and hour, which are numbers, and to specific quantities of weight and passengers, also numbers, leaves out the whole complex operation of any particular flight: these numbers tell nothing about the captain, or the Gemütlichkeit of a particular flight that the stewardesses stimulated by serving the passengers champagne. These are true experiences of fact. There is nothing abstract or numerical about the floating sensation one has on deplaning after too much champagne. The numbers and data organization the airlines have built up to keep track of their flights might be used to describe missile flights or perhaps flights from a beehive. The automation of information retrieval is a matter of starting from one point which can be defined without ambiguity and arriving at another point which is also defineable without ambiguity. However, if we try to deal with concrete situations, like how the captain feels, or what the motives of individual passengers are, we cannot deduce them from the flight numbers.

I want to leap now from airline personnel to books. Every library of any size identifies each book with a call number. One of the fundamental rules of library operation which is never broken, except through error, is that no two books will have the same call number. The call number does more than identify one physical volume from another. Except for the few duplicate copies or reprint editions a library might have, the call number also identifies distinct intellectual content. No two books, no two journal articles are the same. They are the creation of an individual or group. Journal editors and book publishers take pains, perhaps not enough pains, to see to it that anything published is distinctive. Because every book can be identified with a "code" number does not mean that the essence of the book has been abstracted. One of the basic errors of the engineers and documentalists who try to reduce the intellectual content of a library to a computer memory is their failure to see that the call or code number is not an abstract symbol that can be manipulated logically, but stands for something concrete and unique-the experience of the author.

If we are going to use computers to help us with our information problems, we should not be wasting our efforts trying to squeeze all knowledge into one abstract system, unless we admit that we want human beings to be like computers. To make good use of computers we have two tasks before us. One of them already has a long tradition. Bibliographers are constantly examining published knowledge to locate what appears with a recurring regularity and can be abstracted. After all, this is how our reference books get organized. The other task will require new attitudes, if not a new discipline which, incidently, has already been named social epistemology. ${ }^{9}$ We must examine the functioning of our academic and professional groups to find out what kind of information and knowledge they use so it can be organized in new and different ways, as for example, the work of Mediphone which is nothing more than an up-to-date Physician's Desk Reference.

I should like to end by rephrasing an admonition implied in the title of this paper. Mankind, in search for identity, first looked to the stars, trees, and animals. In Western civilization animism was replaced by the Greeks and Hebrews with gods of the spirit who gave man his reason for being. The materialistic scientist brought man to a mechanism whose complete functioning could be explained by knowing the laws of nature. In midtwentieth century, we have a new beast we can anthropomorphize, the computer, which extends man's horizons, but hardly makes his creativity obsolete.

- Jesse Shera, "Social Epistemology, General Semantics and Librarianship," Wilson Library Bulletin, XXXIV (1961), 767-770. 